\title{
Vitamin D and tuberculosis: a multicenter study in children
}

\author{
Elisabetta Venturini ${ }^{1}$, Ludovica Facchini ${ }^{1}$, Nuria Martinez-Alier ${ }^{2}$, Vas Novelli ${ }^{3}$, Luisa Galli ${ }^{1}$, Maurizio de Martino ${ }^{1 *}$ \\ and Elena Chiappini ${ }^{1}$
}

\begin{abstract}
Background: The aim of this study is to evaluate vitamin D levels in children with latent and active TB compared to healthy controls of the same age and ethnical background.

Methods: A multicenter observational study has been conducted in three tertiary care paediatric centres: Anna Meyer Children's University Hospital, Florence, Italy; Evelina London Children's Hospital, London, United Kingdom and Great Ormond Street Hospital, London, United Kingdom. Vitamin D was considered deficient if the serum level was $<25 \mathrm{nmol} / \mathrm{L}$, insufficient between 25 and $50 \mathrm{nmol} / \mathrm{L}$ and sufficient for a level $>50 \mathrm{nmol} / \mathrm{L}$.

Results: The study population included 996 children screened for TB, which have been tested for vitamin D. Forty-four children (4.4\%) had active TB, 138 (13.9\%) latent TB and 814 (81.7\%) were controls. Our study confirmed a high prevalence of hypovitaminosis $D$ in the study population. A multivariate analysis confirmed an increased risk of hypovitaminosis $D$ in children with latent and active TB compared to controls $[(P=0.018 ; R R=1.61 ; 95 \%$ Cl: 1.086-2.388), $(P<0.0001 ; R R=4.587$; 95\% Cl:1.190-9.608)].

Conclusions: Hypovitaminosis D was significantly associated with TB infection in our study. Further studies are needed to evaluate a possible role of vitamin $\mathrm{D}$ in the treatment and prevention of tuberculosis in children.
\end{abstract}

Keywords: Vitamin D, Tuberculosis, Children

\section{Background}

In the pre-antibiotic era, cod liver oil and sunlight exposure were used to treat tuberculosis (TB) [1,2]. More recently, increasing evidences from in vitro studies suggest that vitamin D enhances antimycobacterial immunity [3]. Several authors reported hypovitaminosis D in TB patients [4-6], and serum level of vitamin D [25hydroxycholecalciferol) was found to be lower in TB patients than in healthy controls [7-14]. A recent study conducted among adult TB contacts found that $94 \%$ of recruits were vitamin D insufficient and that a single, oral $2.5 \mathrm{mg}$ dose of vitamin D significantly enhanced their anti-mycobacterial immunity in vitro [7]. Factors such as low socioeconomic status, poor nutrition, traditional/cultural traits, and little exposure to sunlight may contribute to vitamin D deficiency [15].

\footnotetext{
* Correspondence: maurizio.demartino@unifi.it

${ }^{1}$ Department of Health Sciences, University of Florence, Anna Meyer Children's University Hospital, viale Pieraccini 24, I-50139 Florence, Italy Full list of author information is available at the end of the article
}

Mechanisms through which vitamin D modulates the immune system in the response to Mycobacterium tuberculosis infection are not completely understood, two possible mechanisms have emerged as the most likely. Vitamin D appears to reduce the viability of $M$. tuberculosis by enhancing the fusion of the phagosome and lysosome in infected macrophages [16]. In addition, vitamin D may enhance the production of LL-37, an antimicrobial peptide of the cathelicidin family [16-19]. Antimicrobial peptides, such as defensin and cathelicidin, are involved as a first line of defences in the prevention of infections, including tuberculosis. The presence of vitamin $\mathrm{D}$ in neutrophils and macrophages up-regulates in a dose-dependent manner the hCAP-18 gene that codes for LL-37, which suggests that vitamin D induction of LL-37 may play a role in host defences against TB infection $[3,16]$.

Vitamin D exerts its actions through vitamin D receptor (VDR), a nuclear hormone receptor. Polymorphisms in the VDR gene, which may influence VDR activity and subsequent downstream vitamin $\mathrm{D}$ mediated effects, were 
therefore studied as potential candidates of risk markers for various clinical outcomes [20,21].

Clinical trials $[8,10,22-24]$ have been conducted to test whether vitamin D therapy improves TB outcomes, suggesting that vitamin $\mathrm{D}$ may be beneficial as an adjunctive treatment to the traditional therapy in patients with TB; however, additional trials in children need to be conducted to clarify its role [25].

\section{Methods}

A multicenter study was conducted in three tertiary care paediatric centres: Anna Meyer Children's University Hospital, Florence, Italy; Evelina London Children's Hospital, London, United Kingdom and Great Ormond Street Hospital, London, United Kingdom. The data regarding the period of time between July 2008 and January 2013 were collected retrospectively, whereas those between February and September 2013 prospectively. Written informed consent for participation in the study was obtained from children's parent or guardian. The aim of the study was to evaluate vitamin D levels in children with latent and active tuberculosis, compared to healthy controls of the same age and ethnical background. Secondary objective was to evaluate potential differences between groups of patients (considering age, race, enrolling centre, vitamin D supplementation, latent or active tuberculosis).

\section{Study design}

Children (aged $<18$ years) investigated for TB infection between July 2008 and September 2013, for whom vitamin $\mathrm{D}$ was tested during the first visit, were eligible. The reasons for referral to the paediatric infectious diseases centres were clinical suspicious or confirmed TB disease, history of TB contact or immigrated/adopted child from a TB endemic country within the previous 2 years. Children with congenital or acquired immunodeficiency were excluded.

For each child the following data were entered into the study database: name, age, gender, ethnic group, familial and personal history including risk factors for TB infection and for vitamin D deficiency, bacillus CametteGuerin (BCG) vaccination and physical examination. Data about tests performed were also included, in particular vitamin D level (25-hydroxycholecalciferol, 25OHD), tuberculin skin test (TST), interferon $-\gamma$ release assay (IGRA), and if available calcium, phosphate, chest $\mathrm{x}$-ray, chest computerised tomography, gastric aspirate or sputum (microscopy, culture and polymerase chain reaction for $M$. tuberculosis) and anti-tubercular treatment. All results were recorded in the study database following the international standards for the protection of privacy and personal information.

\section{Ethical issues}

This study was approved by the Ethical Committees of the hospitals involved: Anna Meyer Children's University Hospital, Florence, Italy; Evelina London Children's Hospital, London, United Kingdom and Great Ormond Street Hospital, London, United Kingdom.

\section{Case definitions TB disease}

Active TB diagnosis was assigned to any child with $M y c o-$ bacterium tuberculosis cultured or detected by microscopy or molecular methods from sputum, gastric aspirate or other biologic samples. Active TB diagnosis was also assigned to any child with clinical and radiological evidence of TB disease, and with either a history of exposure to an infectious case or a positive TST. In the absence of a recognized gold standard, latent tuberculosis diagnosis was assigned to any child with a positive TST and/or IGRA and no clinical, bacteriological or radiographic evidence of active TB [26]. In the absence of those criteria children were included in the control group.

\section{Hypovitaminosis D}

Vitamin D level was evaluated testing for 25-OHD, which is considered its best indicator [27]. Following the European Society for Paediatric Gastroenterology, Hepatology and Nutrition (ESPGHAN) definition, 25-OHD was considered deficient in case of a serum vitamin $\mathrm{D}$ level less than $25 \mathrm{nmol} / \mathrm{L}$, insufficient between 25 and $50 \mathrm{nmol} / \mathrm{L}$ and sufficient for level above $50 \mathrm{nmol} / \mathrm{L}$ [28].

\section{Statistical analysis}

Continuous measurements analyzed were: age (years), weight (kilograms), height (centimetres), 25-OHD serum level ( $\mathrm{nmol} / \mathrm{L})$, calcium and phosphate levels ( $\mathrm{mmol} / \mathrm{L})$. Median and interquartile range (IQR) were calculated for those variables in the study groups. Categorical data were compared using the Chi-squared test (or Fisher's exact test, when expected cell sizes were smaller than five). The Wilcoxon-Mann-Whitney test was used for continuous measurements to test relationships in unpaired analysis, when assumed that the dependent variable was a not normally distributed interval variable. Moreover, the risk factors for vitamin D deficiency were evaluated using univariate and multivariate logistic regression. The variables included in the analysis were: TB infection status (active TB, latent $\mathrm{TB}$, and control), gender, age, ethnicity at risk for vitamin $\mathrm{D}$ deficiency, immigration, seasonality (categorized ad autumnwinter and spring-summer). For each factor the relative risk (RR) and 95\% confident intervals (95\% CI) were evaluated. Statistical analysis was performed using the statistical software SPSS for Windows, version 12.0. P <0.05 was considered statistically significant. 


\section{Results \\ Population}

Nine hundred and ninety-six children were included in this study: 15 (1.5\%) from Great Ormond Street Hospital, London, UK; 63 (6.4\%) from Evelina London Children's Hospital, London, UK; and 918 (92.1\%) from Anna Meyer Children's University Hospital, Florence, Italy. The study population characteristics are summarized in Table 1.

\section{TB status}

Forty-four (4.4\%) children met the criteria for active TB. The most common condition was pulmonary TB $(n=24$; $54.5 \%)$. Extra-pulmonary TB was in order of frequency: lymphadenitis $(\mathrm{n}=5 ; 11.4 \%)$, pleural-peritoneal $(\mathrm{n}=4$; $9.1 \%)$, skeletal ( $n=4 ; 9.1 \%)$, ocular $(n=1 ; 2.3 \%)$, meningeal $(\mathrm{n}=1 ; 2.3 \%)$. Miliary TB was found in 5 patients $(11.4 \%)$. The median length of the treatment was 7 months (range 6-12). Quadruple therapy (isoniazid, rifampicin, ethambutol, pyrazinamide) was used in 36 children, in 4 of those in association with steroids. In other 8 cases different antiTB treatment associations have been used, mostly because of resistant mycobacteria.

One hundred and thirty-eight (13.9\%) children met the criteria for latent TB. Double therapy (isoniazid and rifampicin) for 3 months was the commonest combination used $(91.3 \%, \mathrm{n}=126)$. The controls enrolled in the study were $814(81.7 \%)$.

\section{Vitamin D, calcium and phosphate levels in the study groups}

Vitamin D levels in the different study groups are reported in Table 2 and illustrated in Figure 1. About half (467; $46.9 \%$ ) of the children tested, independently from the TB status, resulted to have an insufficient or deficient vitamin D level. Hypovitaminosis D was found respectively in 354 (43.5\%) of controls, 80 (58\%) latent TB and 33 (75\%) active TB. The statistical analysis with the Mann-Whitney U test showed that vitamin D level was significantly lower in case of latent and active TB compared to controls ( $p<0.0001)$, with median level respectively of $45 \mathrm{nmol} / \mathrm{L}$ (IQR: $30-$ 62.5), $27.8 \mathrm{nmol} / \mathrm{L}$ (IQR: 19-50) and $52.5 \mathrm{nmol} / \mathrm{L}$ (IQR: 31.5-67.5).

Vitamin D levels were significantly lower in latent TB compared to controls $(\mathrm{p}=0.002)$, in active TB compared to controls $(\mathrm{p}<0.0001)$ and in active TB compared to latent TB $(\mathrm{p}=0.001)$.

Moreover, a deficient vitamin $\mathrm{D}$ level was found in higher percentage in the active TB group ( $\mathrm{n}=18 ; 40.9 \%)$ compared to latent TB $(\mathrm{n}=28 ; 20.3 \%)$ and controls (13.9\%) $(\mathrm{P}<0.0001)$. An insufficient level of vitamin $\mathrm{D}$ was more frequently found in the latent TB group $(\mathrm{n}=$ $113 ; 37.7 \%, \mathrm{P}<0.0001$ ) (Figure 2).
All the variable analysed were statistically significant also according to the US Endocrinology Society vitamin D status classification $(\mathrm{P}<0.0001)(29)$.

Calcium and phosphate levels (median and IQR) in the different study groups are reported in Table 2.

In the study population 159 (16\%) children were vitamin D deficient, 308 (30.9\%) insufficient and 529 (53.1\%) sufficient.

The correlation between vitamin D status and other factors (age, gender, seasonality, calcium and phosphate levels) has been reported in Table 3.

Vitamin D level was significantly lower if tested during Autumn-Winter compared to Spring-Summer $(\mathrm{P}<0.0001)$ (Figure 3).

\section{Multivariate analysis}

A multivariate logistic regression analysis was used to exclude possible confounding factors. This analysis confirmed the risk of vitamin D deficiency to be statistically correlated with $\mathrm{TB}$ infection $(\mathrm{RR}=1.61$; 95\% CI:1.0862.388; $\mathrm{P}=0.018$;), and higher in active $\mathrm{TB}$ compared to latent $\mathrm{TB}$ and controls, ( $\mathrm{RR}=4.587$; 95\% CI: 1.190 9.608; $\mathrm{P}<0.0001)$. In the multivariate analysis the results were adjusted for the different centres.

There was no significant correlation between hypovitaminosis $\mathrm{D}$ and gender $(\mathrm{P}=0.113$; $\mathrm{RR}=0.799$; 95\% CI: 0.605 1.055), ethnicity at risk of hypovitaminosis $\mathrm{D}(\mathrm{P}=0.688$; $\mathrm{RR}=1.610 ; \quad 95 \% \quad \mathrm{CI}: \quad 0.715-1.747)$ and immigration ( $\mathrm{P}=0.428 ; \mathrm{RR}=1.316$; 95\% CI: $0.668-2.590)$. On the contrary, a correlation between hypovitaminosis $\mathrm{D}$ and age $(\mathrm{P}<0.0001 ; \mathrm{RR}=1.147 ; 95 \% \mathrm{CI}: 1.105-1.190)$ and between vitamin $\mathrm{D}$ deficiency and seasonality $(\mathrm{P}<0.0001$; $\mathrm{RR}=2.208$; 95\% CI: 2.132-3.698) was found.

\section{Vitamin D supplementation}

In case of hypovitaminosis D, different vitamin D supplementation protocols were used in the three centres, according with the most recent international guidelines [28-31]. At Anna Meyer Children's University Hospital, Florence, Italy, 1000 IU of colecalciferol were administered daily for 8 weeks. At Evelina London Children's Hospital, London, UK, 3,000, 6,000, 10,000 or 20,000 IU of colecalciferol were used daily for 6 weeks depending on the severity of hypovitaminosis D. At Great Ormond Street Hospital, London, UK 50,000 IU of ergocalciferol were administered daily for 3 to 6 days.

Only one-third $(133 ; 28.5 \%)$ of the patients with a low level of vitamin D received vitamin D supplementation. Vitamin D supplementation was prescribed in 71 controls, 36 latent TB and 26 active TB, respectively 20\%, $45 \%$ and $79 \%$ of children with hypovitaminosis D in the 3 different groups. 
Table 1 Study population characteristics

\begin{tabular}{|c|c|c|c|c|c|}
\hline & Controls $\mathrm{n}=814$ & Latent TB $n=138$ & Active TB $n=44$ & Total $\mathrm{n}=996$ & $\mathbf{P}$ \\
\hline Enrolling centre, $n(\%)$ : & & & & & $<0.0001$ \\
\hline - Evelina London Children's & $21(2.6 \%)$ & $25(18.1 \%)$ & $17(38.6 \%)$ & $63(6.4 \%)$ & \\
\hline \multicolumn{6}{|l|}{ Hospital, London, UK } \\
\hline - Great Ormond Street & $0(0 \%)$ & $0(0 \%)$ & $15(34.1 \%)$ & $15(1.5 \%)$ & \\
\hline \multicolumn{6}{|l|}{ Hospital, London, UK } \\
\hline - Anna Meyer Children's University Hospital, Florence, Italy & $793(97.4 \%)$ & $113(81.9 \%)$ & $12(27.3 \%)$ & $918(92.1 \%)$ & \\
\hline Age in years, median (IQR) & $5.5(3.1-8.1)$ & $6.9(4.3-10.8)$ & $4.7(3.0-11.6)$ & $5.8(3.1-8.5)$ & $<0.0001$ \\
\hline Gender, n (\%): & & & & & $<0.0001$ \\
\hline - Male & $496(60.9 \%)$ & $85(61.6 \%)$ & $15(34.1 \%)$ & $596(59.4 \%)$ & \\
\hline - Female & $310(38.1 \%)$ & $52(37.7 \%)$ & $29(65.9 \%)$ & 391 (39.6\%) & \\
\hline - Not known & $8(1 \%)$ & $1(0.7 \%)$ & $0(0 \%)$ & $9(0.9 \%)$ & \\
\hline Country of origin*, n (\%): & & & & & $<0.0001$ \\
\hline - Asia & $146(17.9 \%)$ & 19 (13.8\%) & $4(9.1 \%)$ & $169(17 \%)$ & \\
\hline - Latin America & $183(22.5 \%)$ & $24(17.4 \%)$ & $4(9.1 \%)$ & $211(21.2 \%)$ & \\
\hline - Eastern Europe§ & 269 (33\%) & $57(41.3 \%)$ & $5(11.4 \%)$ & $331(33.2 \%)$ & \\
\hline - Western Europe & $36(4.4 \%)$ & $7(5.1 \%)$ & $3(6.8 \%)$ & $46(4.6 \%)$ & \\
\hline - Nord Africa & $16(2 \%)$ & $1(0.7 \%)$ & $2(4.5 \%)$ & $19(1.9 \%)$ & \\
\hline - Sub-Saharan Africa & $151(18.6 \%)$ & $29(21 \%)$ & $25(56.8 \%)$ & $205(20.6 \%)$ & \\
\hline - Other & $8(1 \%)$ & $0(0 \%)$ & $0(0 \%)$ & $8(0.8 \%)$ & \\
\hline - Not known & $5(0.6 \%)$ & $1(0.7 \%)$ & $1(2.3 \%)$ & $7(0.7 \%)$ & \\
\hline Ethnic group, n (\%): & & & & & $<0.0001$ \\
\hline - African & $168(20.7 \%)$ & $30(21.7 \%)$ & $27(61.4 \%)$ & $225(22.6 \%)$ & \\
\hline - Asiatic & $146(17.9 \%)$ & 19 (13.8\%) & $4(9.1 \%)$ & $169(17 \%)$ & \\
\hline - Caucasian & $306(37.6 \%)$ & $64(46.4 \%)$ & $8(18.2 \%)$ & $378(37.9 \%)$ & \\
\hline - Hispanic & $183(22.5 \%)$ & $24(17.4 \%)$ & $4(9.1 \%)$ & $211(21.2 \%)$ & \\
\hline - Other & $6(0.7 \%)$ & $0(0 \%)$ & $0(0 \%)$ & $6(0.6 \%)$ & \\
\hline - Not known & $5(0.6 \%)$ & $1(0.7 \%)$ & $1(2.2 \%)$ & $7(0.7 \%)$ & \\
\hline BCG, n (\%): & & & & & 0.109 \\
\hline - Yes & $460(56.5 \%)$ & $89(64.5 \%)$ & $20(45.5 \%)$ & $569(57.1 \%)$ & \\
\hline - No & $244(30.0 \%)$ & $40(29.0 \%)$ & 19 (43.2\%) & $303(30.4 \%)$ & \\
\hline - Not known & $110(13.5 \%)$ & $9(6.5 \%)$ & $5(11.4 \%)$ & $124(12.4 \%)$ & \\
\hline Risk factors for vitamin $D$ & & & & & 0.932 \\
\hline \multicolumn{6}{|l|}{ deficiencyt, n (\%): } \\
\hline - Yes & $470(57.7 \%)$ & $74(53.6 \%)$ & $32(72.7 \%)$ & $576(57.8 \%)$ & \\
\hline- No & $344(42.3 \%)$ & $64(46.4 \%)$ & $12(27.3 \%)$ & $420(42.2 \%)$ & \\
\hline Risk factors for TB & & & & & $<0.0001$ \\
\hline \multicolumn{6}{|l|}{ infection, n (\%): } \\
\hline - Tb contact & $92(11.4 \%)$ & $31(22.5 \%)$ & $27(21.2 \%)$ & $150(15.1 \%)$ & \\
\hline - Travel to/immigrated from & $695(85.3 \%)$ & $104(75.4 \%)$ & $10(22.8 \%)$ & $809(80.1 \%)$ & \\
\hline \multicolumn{6}{|l|}{ TB endemic country } \\
\hline - Not known & $27(3.3 \%)$ & $3(2.1 \%)$ & $7(15.9 \%)$ & 37 (3.7\%) & \\
\hline IGRA, n (\%): & & & & & $<0.0001$ \\
\hline - Positive & $0(0.0 \%)$ & $45(32.6 \%)$ & $28(63.6 \%)$ & $73(7.3 \%)$ & \\
\hline
\end{tabular}


Table 1 Study population characteristics (Continued)

\begin{tabular}{lllll}
\hline - Negative & $792(97.3 \%)$ & $71(51.4 \%)$ & $7(15.9 \%)$ & $870(87.3 \%)$ \\
- Not known & $22(2.7 \%)$ & $22(15.9 \%)$ & $9(20.5 \%)$ & $53(5.3 \%)$ \\
TST, $\mathbf{n}(\%):$ & & & $32(72.7 \%)$ & $152(15.3 \%)$ \\
- Positive & $0(0.0 \%)$ & $120(87 \%)$ & $2(4.5 \%)$ & $789(79.2 \%)$ \\
- Negative & $777(95.5 \%)$ & $10(7.2 \%)$ & $10(22.7 \%)$ & $55(55.2 \%)$ \\
- Not known & $37(4.5 \%)$ & $8(5.8 \%)$ & 0.0001 \\
\hline
\end{tabular}

*Whether the child's family is originally from a TB endemic country, this has been indicated as country of origin, independently from the country of birth. §Albania, Belarus, Bulgaria, Kosovo, Macedonia, Moldavia, Poland, Czech Republic, Romania, Russia, Serbia, Slovakia, Slovenia, Ukraine, Hungary. †African, Asiatic and Hispanic ethnic group.

\section{Discussion}

The high prevalence of hypovitaminosis $\mathrm{D}$ in children $[32,33]$ is confirmed in our study, based on a large data set, reaching $47 \%$ of children tested, independently from their TB status.

The correlation between vitamin D deficiency and TB disease was previously demonstrated in adults [4-6,8-14], although some authors do not agree with this hypothesis [34-40]. No paediatric study with a matched control group is available in literature, and our study's aim is to fill this gap. Three studies on a possible correlation between vitamin $\mathrm{D}$ deficiency and $\mathrm{TB}$ in the paediatric population were previously published [41-43], including overall 442 children. In the first study on refugee children, a vitamin D level was significantly lower in 92 children with TB infection compared to 236 healthy controls [41]. The main limitations of this retrospective study were the omission of routine IGRA testing in the definition of TB status and the missing data about BCG vaccination [41]. Hypovitaminosis D prevalence in latent and active TB was $86 \%$ in a retrospective study on 64 children [42]. The principal limitation of this study was the lack of an age and ethnically matched control group without a history of TB infection or disease [42]. Finally, in a randomised study, done on a small number of children $(n=24)$, vitamin D supplementation (colecalciferol $1000 \mathrm{UI}$ daily for 8 weeks) was added to $\mathrm{TB}$ treatment, leading to clinical and radiological improvement compared to the standard treatment alone [43].
The correlation between low vitamin D and TB disease is confirmed in our study on a large paediatric population including a matched control group. Hypovitaminosis $\mathrm{D}$ affected up to $75 \%$ children with active $\mathrm{TB}(\mathrm{P}<$ $0.0001)$. Moreover, the active TB group exhibited the lowest level of vitamin D. Hypovitaminosis D was four times more likely in children with active TB compared to healthy controls. This correlation was confirmed using a multivariate logistic regression analysis, in order to exclude possible confounding factors, and the results were adjusted considering also the different enrolling centre.

About two-third of the study population ethnicity was at high risk for vitamin D deficiency (African, Asiatic and Hispanic). It is well known that the major risk factors in these populations are dark skin, reduced exposure to sunlight due to long clothing and vegetarian diet [32]. The ethnical background at risk of hypovitaminosis D were homogeneously distributed in the 3 study groups. Interestingly, in our study hypovitaminosis D occurred also in the Caucasian group, accounting for about one-third of the cases. Vitamin D was deficient in $32.7 \%$ of Caucasian children and insufficient in 37.3\%. Moreover, about $80 \%$ of children tested in the UK had hypovitaminosis D (respectively $43.6 \%$ was vitamin D deficient and $35.9 \%$ insufficient) compared to $44.1 \%$ of children tested in Italy (respectively $13.6 \%$ was vitamin D deficient and $30.5 \%$ insufficient). This difference could be mainly explained by lower sun exposure in UK with

Table 2 Vitamin D, calcium and phosphate levels in the different study groups

\begin{tabular}{|c|c|c|c|c|c|}
\hline & Controls $\mathrm{n}=814$ & Latent TB $n=138$ & Active TB $n=44$ & Total $\mathrm{n}=996$ & $\mathbf{P}$ \\
\hline Vitamin D level, n (\%): & & & & & 0.0001 \\
\hline - Deficient $(<25 \mathrm{nmol} / \mathrm{L})$ & $113(13.9 \%)$ & $28(20.3 \%)$ & $18(40.9 \%)$ & $159(16 \%)$ & \\
\hline - Insufficient (25-50 nom//L) & $241(29.6 \%)$ & $52(37.7 \%)$ & $15(34.1 \%)$ & $308(30.9 \%)$ & \\
\hline - Sufficient (>50 nmol/L) & $460(56.5 \%)$ & $58(42 \%)$ & $11(25 \%)$ & $529(53.1 \%)$ & \\
\hline Vitamin D level (nmol/L), median (IQR) & $52.5(31.5-67.5)$ & $45(30-62.5)$ & $27.8(19-50)$ & $35(24-54.5)$ & 0.0001 \\
\hline Calcium (mmol/L), median (IQR) & $2.38(2.3-2.45)$ & $2.38(2.3-2.42)$ & $2.35(2.25-2.45)$ & $2.4(2.26-2.46)$ & 0.709 \\
\hline Phosphate (mmol/L), median (IQR) & $1.62(1.49-1.71)$ & $1.75(1.32-1.78)$ & $1.42(1.23-1.6)$ & $1.5(1.28-1.61)$ & 0.002 \\
\hline
\end{tabular}




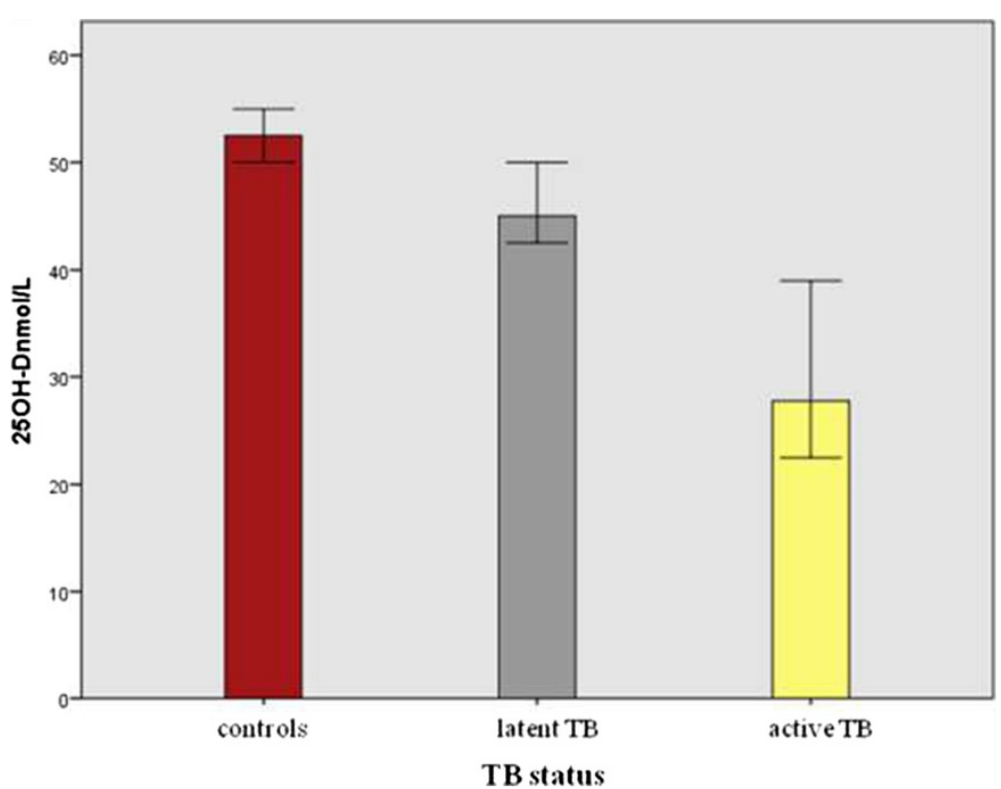

Figure 1 Vitamin D levels (median and IQR) in the different study groups. About half (467; 46.9\%) of the children tested, independently from the TB status, resulted to have an insufficient or deficient vitamin D level. Hypovitaminosis D was found respectively in 354 (43.5\%) of controls, 80 (58\%) latent TB and 33 (75\%) active TB.

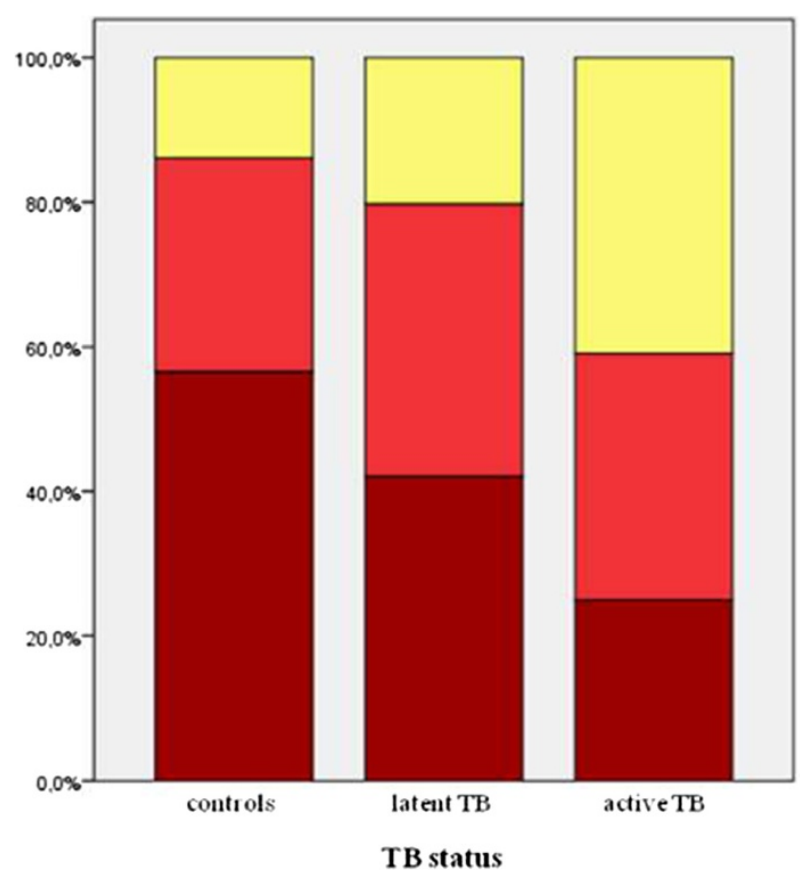

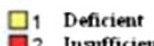

2 Insufficient

TB status

Figure 2 Vitamin D status defined by ESPGHAN according to TB status. A deficient vitamin D level was found in higher percentage in the active TB group $(n=18 ; 40.9 \%)$ compared to latent TB $(n=28 ; 20.3 \%)$ and controls $(13.9 \%)(P<0.0001)$. An insufficient level of vitamin $D$ was more frequently found in the latent TB group $(n=113 ; 37.7 \%, P<0.0001)$. 
Table 3 Characteristics of the population according to vitamin D status

\begin{tabular}{|c|c|c|c|c|c|}
\hline & Deficient $n=159$ & Insufficient $\mathrm{n}=308$ & Sufficient $n=529$ & Total $\mathbf{n}=996$ & $\mathbf{P}$ \\
\hline TB status, $n(\%):$ & & & & & $<0.0001$ \\
\hline - Controls & $113(71.1 \%)$ & $241(78.2 \%)$ & $460(87 \%)$ & $814(81.7 \%)$ & \\
\hline - Latent TB & $28(17.6 \%)$ & $52(16.9 \%)$ & $58(11 \%)$ & $138(13.9 \%)$ & \\
\hline - Active TB & $18(11.3 \%)$ & $15(4.9 \%)$ & $11(2 \%)$ & $44(4.4 \%)$ & \\
\hline Enrolling centre, $n(\%)$ : & & & & & $<0.0001$ \\
\hline - Evelina London Children's & $26(16.4 \%)$ & $23(7.5 \%)$ & $14(2.6 \%)$ & $63(6.4 \%)$ & \\
\hline \multicolumn{6}{|l|}{ Hospital, London, UK } \\
\hline - Great Ormond Street & $8(5 \%)$ & $5(1.6 \%)$ & $2(0.4 \%)$ & $15(1.5 \%)$ & \\
\hline \multicolumn{6}{|l|}{ Hospital, London, UK } \\
\hline - Anna Meyer Children's University Hospital, Florence, Italy & $125(78.6 \%)$ & $280(90.9 \%)$ & $513(97 \%)$ & 918 (92.1\%) & \\
\hline Age, median (IQR) & $6.5(4.2-10.3)$ & $6.6(4-9.7)$ & $4.8(2.5-7.6)$ & $5.8(3.1-8.5)$ & $<0.0001$ \\
\hline Gender, n (\%): & & & & & 0.106 \\
\hline - Male & $85(53.5 \%)$ & 182 (59.1\%) & $329(62.2 \%)$ & $596(59.8 \%)$ & \\
\hline - Female & $74(46.5 \%)$ & $122(39.6 \%)$ & 195 (36.9\%) & 391 (39.3\%) & \\
\hline - Not known & $0(0 \%)$ & $4(1.3 \%)$ & $5(0.9 \%)$ & $9(0.9 \%)$ & \\
\hline Country of origin*, n (\%): & & & & & $<0.0001$ \\
\hline - Asia & $27(17 \%)$ & $44(14.3 \%)$ & $98(18.5 \%)$ & $169(17 \%)$ & \\
\hline - Latin America & $25(15.7 \%)$ & $74(24 \%)$ & $112(21.2 \%)$ & $211(21.2 \%)$ & \\
\hline - Eastern Europe $\S$ & $48(30.2 \%)$ & 95 (30.8\%) & $188(35.5 \%)$ & 331 (33.2\%) & \\
\hline - Western Europe & $4(2.5 \%)$ & $18(5.8 \%)$ & $24(4.5 \%)$ & $46(4.6 \%)$ & \\
\hline - Nord Africa & $7(4.4 \%)$ & $8(2.6 \%)$ & $4(0.8 \%)$ & 19 (1.9\%) & \\
\hline - Sub-Saharan Africa & $42(26.4 \%)$ & $65(21.1 \%)$ & $98(18.5 \%)$ & 205 (20.6\%) & \\
\hline - Other & $1(0.6 \%)$ & $3(1 \%)$ & $4(0.8 \%)$ & $8(0.8 \%)$ & \\
\hline - Not known & $5(3.1 \%)$ & $1(0.3 \%)$ & $1(0.2 \%)$ & $7(0.7 \%)$ & \\
\hline Ethnic group, n (\%): & & & & & $<0.0001$ \\
\hline - African & $50(30.8 \%)$ & $74(24 \%)$ & $101(19.1 \%)$ & $225(22.6 \%)$ & \\
\hline - Asiatic & $24(15.1 \%)$ & $43(14 \%)$ & $102(19.3 \%)$ & $169(17 \%)$ & \\
\hline - Caucasian & $52(32.7 \%)$ & 115 (37.3\%) & $211(39.9 \%)$ & $378(37.9 \%)$ & \\
\hline - Hispanic & $27(17 \%)$ & $73(23.7 \%)$ & $111(21 \%)$ & $211(21.2 \%)$ & \\
\hline - Other & $1(1.2 \%)$ & $2(0.7 \%)$ & $3(0.5 \%)$ & $6(0.6 \%)$ & \\
\hline - Not known & $5(3.2 \%)$ & $1(0.3 \%)$ & $1(0.2 \%)$ & $7(0.7 \%)$ & \\
\hline Risk factors for vitamin $D$ & & & & & 0.932 \\
\hline \multicolumn{6}{|l|}{ deficiencyt, n (\%): } \\
\hline - Yes & $93(58.5 \%)$ & $180(58.4 \%)$ & $303(57.3 \%)$ & $576(57.8 \%)$ & \\
\hline- No & $66(41.5 \%)$ & $128(41.6 \%)$ & $226(42.7 \%)$ & $420(42.2 \%)$ & \\
\hline Season when blood test was & & & & & $<0.0001$ \\
\hline \multicolumn{6}{|l|}{ done, $n(\%)$ : } \\
\hline - Spring-Summer & $58(36.5 \%)$ & $145(47.1)$ & $339(64.1 \%)$ & $542(54.4 \%)$ & \\
\hline - Winter-Autumn & $101(63.5 \%)$ & $163(52.9)$ & $190(35.9 \%)$ & $454(45.6 \%)$ & \\
\hline Vitamin D level (nmol/L), median (IQR) & $20(15.5-22.5)$ & $37.5(32.5-42.5)$ & $72.5(57.5-87.5)$ & $35(24-54.5)$ & \\
\hline Calcium (mmol/L), median (IQR) & $2.35(2.28-2.42)$ & $2.37(2.3-2.43)$ & $2.38(2.33-2.48)$ & $2.4(2.26-2.46)$ & 0.030 \\
\hline Phosphate (mmol/L), median (IQR) & $1.5(1.3-1.65)$ & $1.59(1.41-1.68)$ & $1.65(1.49-1.81)$ & $1.5(1.28-1.61)$ & 0.001 \\
\hline
\end{tabular}

*Whether the child's family is originally from a TB endemic country, this has been indicated as country of origin, independently from the country of birth. §Albania, Belarus, Bulgaria, Kosovo, Macedonia, Moldavia, Poland, Czech Republic, Romania, Russia, Serbia, Slovakia, Slovenia, Ukraine, Hungary. tAfrican, Asiatic and Hispanic ethnic group. 


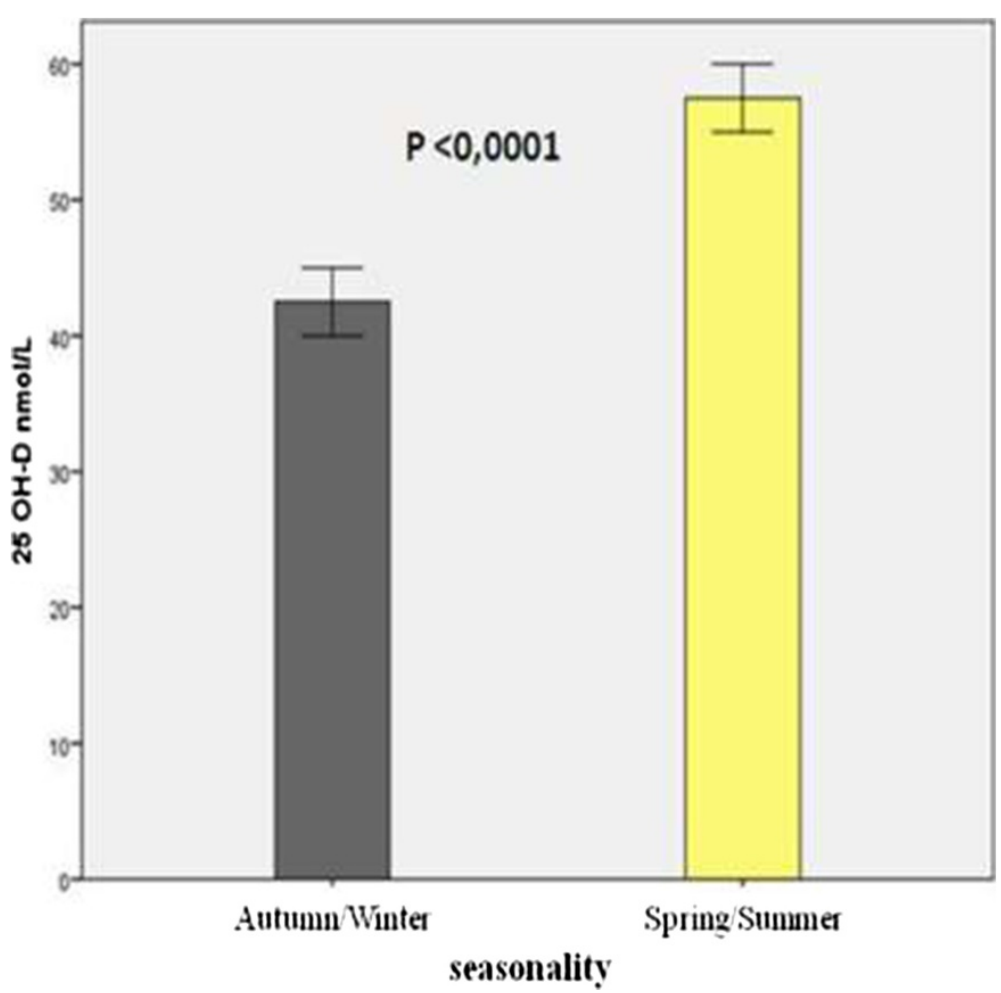

Figure 3 Vitamin D level according to seasonality. Vitamin D level was significantly lower if tested during Autumn-Winter compared to Spring-Summer $(P<0.0001)$.

respect to Italy and probably also by different diet within the two countries. However, the high percentage of hypovitaminosis in Italy despite good sun exposure, affecting about half of the children tested, should increase the awareness of this problem also in countries known to be at low risk for vitamin $\mathrm{D}$ deficiency.

Hypovitaminosis D was statistically more frequent if tested during autumn and winter compared to spring and summer. This seasonality has been well described and is mainly related to sun exposure $[6,12,41,44]$.

Surprisingly, only one-third of the patients with hypovitaminosis D received vitamin D supplementation, with different protocols depending on the prescribing centre. The protocols used in the three centres were in agreement with the most recent international guidelines [28-31]. This data should alert the physicians about the need of vitamin $\mathrm{D}$ supplementation in children with hypovitaminosis, to prevent rickets and its complications. However no clinical sign of rickets was reported in our study population. The choice of vitamin D regimen in the paediatric population should take count of compliance, especially in young children and in TB patients, which already receive a significant amount of drugs. The need of clear guidelines for children with hypovitaminosis D in this setting should be addressed, in order to unify the management of vitamin D supplementation in this group of patients.
The major limitations of our study are: the lack of homogeneity between the study groups, as the majority of controls were enrolled in the Italian centre. To minimize the influence of this factor on our results a multivariate analysis was performed, including the enrolling centre as a categorical variable. Moreover data regarding parathyroid hormone, alkaline phosphatase were lacking. In our study the hypovitaminosis D definition used was in keeping with ESPGHAN guidelines [28], although we were aware about different definitions. To avoid this bias we performed the analysis considering also vitamin D status classification by the US Endocrine Society [29], and the results didn't change substantially.

\section{Conclusions}

Our large population study confirms an increasing incidence of hypovitaminosis D in Europe, within native and immigrated children, and the role played by vitamin $\mathrm{D}$ status in TB disease.

In our study hypovitaminosis D was significantly associated with TB infection. Further studies are needed to evaluate a possible role of vitamin D in the treatment and prevention of tuberculosis in children, especially novel randomized controlled trials to compare TB treatment outcomes in children receiving vitamin D supplementation in addition to the standard therapy. 


\section{Abbreviations}

25-OHD: 25-Hydroxycholecalciferol; BCG: Bacillus Calmette-Guerin; Cl: Confidence intervals; ESPGHAN: European Society for Paediatric Gastroenterology, Hepatology and Nutrition; IGRA: Interferon- $\gamma$ release assay; IQR: Interquartile range; RR: Relative risk; TB: Tuberculosis; TST: Tuberculin skin test; VDR: Vitamin D receptor

\section{Competing interests}

The authors declare that they have no competing interests.

\section{Authors' contributions}

EV, EC have made substantial contributions to conception and design of the study; LF in the acquisition of data; MdM, LG, VN and NMA in the analysis and interpretation of data; EV, LG and EC have been involved in drafting the manuscript; MdM and VN were involved in revising critically the paper for the scientifical part. Each author participated sufficiently in the work to take public responsibility for appropriate portions of the content. Each author gave a final approval of the version to be published.

\section{Author details}

${ }^{1}$ Department of Health Sciences, University of Florence, Anna Meyer Children's University Hospital, viale Pieraccini 24, I-50139 Florence, Italy. 'Evelina London Children's Hospital, Guy's and St Thomas' NHS Foundation Trust, London, UK. ${ }^{3}$ Department of Infectious Diseases, Great Ormond Street Hospital for Children NHS Trust, Great Ormond Street, London WC1N 3JH, UK.

Received: 1 June 2014 Accepted: 21 November 2014

Published online: 11 December 2014

\section{References}

1. Roelandts R: The history of phototherapy: something new under the sun? J Am Acad Dermatol 2002, 46:926-930.

2. Grad R: Cod and the consumptive: a brief history of cod-liver oil in the treatment of pulmonary tuberculosis. Pharm Hist 2004, 46:106-120.

3. Liu PT, Stenger S, Li H, Wenzel L, Tan BH, Krutzik SR, Ochoa MT, Schauber J, Wu K, Meinken C, Kamen DL, Wagner M, Bals R, Steinmeyer A, Zügel U, Gallo RL, Eisenberg D, Hewison M, Hollis BW, Adams JS, Bloom BR, Modlin RL: Toll-like receptor triggering of a vitamin D-mediated human antimicrobial response. Science 2006, 311:1770-1773.

4. Talat N, Perry S, Parsonnet J, Dawood G, Hussain R: Vitamin D deficiency and tuberculosis progression. Emerg Infect Dis 2010, 16:853-855.

5. Martineau AR, Timms PM, Bothamley GH, Hanifa Y, Islam K, Claxton AP Packe GE, Moore-Gillon JC, Darmalingam M, Davidson RN, Milburn HJ, Baker LV, Barker RD, Woodward NJ, Venton TR, Barnes KE, Mullett CJ, Coussens AK, Rutterford CM, Mein CA, Davies GR, Wilkinson RJ, Nikolayevskyy V, Drobniewski FA, Eldridge SM, Griffiths CJ: High-dose vitamin D(3) during intensive-phase antimicrobial treatment of pulmonary tuberculosis: a double-blind randomised controlled trial. Lancet 2011, 377:242-250.

6. Martineau AR, Nhamoyebonde S, Oni T, Rangaka MX, Marais S, Bangani N, Tsekela R, Bashe L, de Azevedo V, Caldwell J, Venton TR, Timms PM, Wilkinson KA, Wilkinson RJ: Reciprocal seasonal variation in vitamin D status and tuberculosis notifications in Cape Town, South Africa. Proc Natl Acad Sci U S A 2011, 108:19013-19017.

7. Martineau AR, Wilkinson RJ, Wilkinson KA, Newton SM, Kampmann B, Hall BM, Packe GE, Davidson RN, Eldridge SM, Maunsell ZJ, Rainbow SJ, Berry JL, Griffiths CJ: A single dose of vitamin D enhances immunity to mycobacteria. Am J Respir Crit Care Med 2007, 176:208-213.

8. Davies PD, Brown RC, Woodhead JS: Serum concentrations of vitamin D metabolites in untreated tuberculosis. Thorax 1985, 40:187-190.

9. Davies PD, Church HA, Brown RC, Woodhead JS: Raised serum calcium in tuberculosis patients in Africa. Eur J Respir Dis 1987, 71:341-344.

10. Wilkinson RJ, Llewelyn M, Toossi Z, Patel P, Pasvol G, Lalvani A, Wright D, Latif M, Davidson RN: Influence of vitamin D deficiency and vitamin D receptor polymorphisms on tuberculosis among Gujarati Asians in west London: a case-control study. Lancet 2000, 355:618-621.

11. Sasidharan PK, Rajeev E, Vijayakumari V: Tuberculosis and vitamin D deficiency. J Assoc Physicians India 2002, 50:554-558.

12. Sita-Lumsden A, Lapthorn G, Swaminathan R, Milburn HJ: Reactivation of tuberculosis and vitamin D deficiency: the contribution of diet and exposure to sunlight. Thorax 2007, 62:1003-1007.
13. Gibney KB, MacGregor L, Leder K: Vitamin D deficiency is associated with tuberculosis and latent tuberculosis infection in immigrants from sub-Saharan Africa. Clin Infect Dis 2008, 46:443-446.

14. Friis $\mathrm{H}$, Range $\mathrm{N}$, Pedersen ML, Mølgaard C, Changalucha J, Krarup H, Magnussen P, Søborg C, Andersen AB: Hypovitaminosis D is common among pulmonary tuberculosis patients in Tanzania but is not explained by the acute phase response. J Nutr 2008, 138:2474-2480.

15. Nnoaham KE, Clarke A: Low serum vitamin D levels and tuberculosis: a systematic review and meta-analysis. Int J Epidemiol 2008, 37:113-119.

16. Chocano-Bedoya P, Ronnenberg AG: Vitamin D and tuberculosis. Nutr Rev 2009, 67:289-293.

17. Martineau AR, Wilkinson KA, Newton SM, Floto RA, Norman AW, Skolimowska K, Davidson RN, Sørensen OE, Kampmann B, Griffiths CJ, Wilkinson RJ: IFN-gamma- and TNF-independent vitamin D-inducible human suppression of mycobacteria: the role of cathelicidin LL-37. J Immunol 2007, 178:7190-7198.

18. Ralph AP, Kelly PM, Anstey NM: L-arginine and vitamin D: novel adjunctive immunotherapies in tuberculosis. Trends Microbiol 2008, 16:336-344.

19. Campbell GR, Spector SA: Vitamin D inhibits human immunodeficiency virus type 1 and Mycobacterium tuberculosis infection in macrophages through the induction of autophagy. PLoS Pathog 2012, 8:1523-1525.

20. Valdivielso JM, Fernandez E: Vitamin D receptor polymorphisms and diseases. Clin Chim Acta 2006, 371:1-12

21. Gao L, Tao Y, Zhang L, Jin Q: Vitamin D receptor genetic polymorphisms and tuberculosis: update systematic review and meta-analysis. Int J Tuberc Lung Dis 2010, 14:15-23.

22. Martineau AR, Honecker FU, Wilkinson RJ, Griffiths CJ: Vitamin D in the treatment of pulmonary tuberculosis. J Steroid Biochem Mol Biol 2007, 103:793-798.

23. Nursyam EW, Amin Z, Rumende CM: The effect of vitamin D as supplementary treatment in patients with moderately advanced pulmonary tuberculous lesion. Acta Med Indones 2006, 38:3-5.

24. Wejse C, Gomes VF, Rabna P, Gustafson P, Aaby P, Lisse IM, Andersen PL, Glerup $H$, Sodemann M: Vitamin D as supplementary treatment for tuberculosis: a double-blind, randomized, placebo-controlled trial. Am J Respir Crit Care Med 2009, 179:843-850.

25. Sinclair D, Abba K, Grobler L, Sudarsanam TD: Nutritional supplements for people being treated for active tuberculosis. Cochrane Database Syst Rev 2011, 11, CD006086.

26. American Academy of Pediatrics: Tuberculosis. In Red Book: 2012 Report of the Committee on Infectious Diseases. Edited by Pickering LK, Baker CJ, Kimberlin DW, Long SS. Elk Grove Village, IL: American Academy of Pediatrics; 2012:680-701.

27. Bikle D: Nonclassic actions of vitamin D. J Clin Endocrinol Metab 2009 94:26-34.

28. Braegger C, Campoy C, Colomb V, Decsi T, Domellof M, Fewtrell M, Hojsak I, Mihatsch W, Molgaard C, Shamir R, Turck D, van Goudoever J, ESPGHAN Committee on Nutrition: Vitamin D in the Healthy Paediatric Population: A Position Paper by the ESPGHAN Committee on Nutrition. J Pediatr Gastroenterol Nutr 2013, 56:692-701

29. Holick MF, Binkley NC, Bischoff-Ferrari HA, Gordon CM, Hanley DA, Heaney RP, Murad MH, Weaver CM, Endocrine Society: Evaluation, Treatment, and Prevention of Vitamin D Deficiency: An Endocrine Society Clinical Practice Guideline. 2011. https://www.endocrine.org/ /media/endosociety/Files/Publications/ Clinical\%20Practice\%20Guidelines/FINAL-Standalone-Vitamin-D-Guideline.pdf.

30. Misra M, Pacaud D, Petryk A, Collett-Solberg PF, Kappy M: Drug and Therapeutics Committee of the Lawson Wilkins Pediatric Endocrine Society. Vitamin D deficiency in children and its management: review of current knowledge and recommendations. Pediatrics 2008, 122(3):98-417.

31. Hochberg Z, Bereket A, Davenport M, de Waal HA D-V, De Schepper J, Levine MA, European Society for Paediatric Endocrinology (ESPE) Bone Club: Consensus development for the supplementation of vitamin D in childhood and adolescence. Horm Res 2002, 58:39-51.

32. Braegger $C$, Campoy $C$, Colomb V, Decsi T, Domellof M, Fewtrell M, ESPGHAN Committee on Nutrition: Vitamin D in the healthy European paediatric population. J Pediatr Gastroenterol Nutr 2013, 56:692-701.

33. Holick MF, Chen TC: Vitamin D deficiency: a worldwide problem with health consequences. Am J Clin Nutr 2008, 87:1080-1086.

34. Grange JM, Davies PD, Brown RC, Woodhead JS, Kardjito T: A study of vitamin $D$ levels in Indonesian patients with untreated pulmonary tuberculosis. Tubercle 1985, 66:187-191. 
35. Chan TY: Osteomalacia during rifampicin and isoniazid therapy is rare in Hong Kong. Int I Clin Pharmacol Ther 1996, 34:533-534.

36. Wejse C, Olesen R, Rabna P, Kaestel P, Gustafson P, Aaby P, Andersen PL, Glerup H, Sodemann M: Serum 25-hydroxyvitamin D in a West African population of tuberculosis patients and unmatched healthy controls. A J Clin Nut 2007, 86:1376-1383.

37. Tostmann A, Wielders JP, Kibiki GS, Verhoef H, Boeree MJ, van der Ven AJ: Serum 25-hydroxy-vitamin D3 concentrations increase during tuberculosis treatment in Tanzania. Int J Tuberc Lung Dis 2010, 14:1147-1152.

38. Nielsen NO, Skifte T, Andersson M, Wohlfahrt J, Søborg B, Koch A, Melbye M, Ladefoged K: Both high and low serum vitamin D concentrations are associated with tuberculosis: a case-control study in Greenland. Br J Nut 2010, 104:1487-1491.

39. Banda R, Mhemedi B, Allain TJ: Prevalence of vitamin D deficiency in adult tuberculosis patients at a central hospital in Malawi. Int I Tuberc Lung Dis 2011, 15:408-410.

40. Nansera D, Graziano FM, Friedman DJ, Bobbs MK, Jones AN, Hansen KE: Vitamin $D$ and calcium levels in Ugandan adults with human immunodeficiency virus and tuberculosis. Int J Tuberc Lung Dis 2011, 15:1522-1527.

41. Gray K, Wood N, Gunasekera H, Sheikh M, Hazelton B, Barzi F, Isaacs D: Vitamin $\mathrm{d}$ and tuberculosis status in refugee children. Pediatr Infect Dis $J$ 2012, 31:521-523.

42. Williams B, Williams AJ, Anderson ST: Vitamin D deficiency and insufficiency in children with tuberculosis. Pediatr Infect Dis J 2008, 27:941-942.

43. Morcos MM, Gabr AA, Samuel S, Kamel M, el Baz M, el Beshry M, Michail RR: Vitamin $\mathrm{D}$ administration to tuberculous children and its value. Boll Chim Farm 1998, 137:157-164.

44. Ralph AP, Lucas RM, Norval M: Vitamin D and solar ultraviolet radiation in the risk and treatment of tuberculosis. Lancet Infect Dis 2013, 13:77-88.

doi:10.1186/s12879-014-0652-7

Cite this article as: Venturini et al: Vitamin D and tuberculosis: a

multicenter study in children. BMC Infectious Diseases 2014 14:652.

\section{Submit your next manuscript to BioMed Central and take full advantage of:}

- Convenient online submission

- Thorough peer review

- No space constraints or color figure charges

- Immediate publication on acceptance

- Inclusion in PubMed, CAS, Scopus and Google Scholar

- Research which is freely available for redistribution

Submit your manuscript at www.biomedcentral.com/submit
C Biomed Central 